https://doi.org/10.11646/zoosymposia.17.1.7

http://zoobank.org/urn:lsid:zoobank.org:pub:C51BC0B3-1623-4D4A-8F26-C957C4AA9D14

\title{
Preliminary report on freshwater oligochaetes from some districts of Tamil Nadu (India), along with DNA barcode sequence of a commercially important oligochaete in Chennai
}

\author{
SANJIB CHAKMA ${ }^{1}$, SVANTE MARTINSSON ${ }^{2}$ SIVABALAN SRINIVASAN ${ }^{1}$, AHMED ARFATH \\ GHANI $^{1}$, ROHIT ADAM ${ }^{1} \&$ MOHAMMED IBRAHIM NAVEED ${ }^{1}$ \\ ${ }^{1}$ Department of Zoology, The New College, Chennai-14, India. \\ ${ }^{2}$ Department of Biological and Environmental Sciences, University of Gothenburg, Gothenburg, Sweden. \\ Email: naveed_newcollege@rediffmail.com
}

\begin{abstract}
A survey of aquatic Oligochaeta was conducted at Thiruvallur, Chennai, Kanchipuram, Villupuram and Nilgiris districts of Tamil Nadu from October 2015 to June 2016. Eleven taxa were recorded from a total of 922 specimens examined, eight of them were identified to species level. Five naidids identified during the present study: Branchiodrilus semperi, Dero dorsalis, Dero digitata, Dero indica and Dero zeylanica, and six tubificid taxa Branchiura sowerbyi, Tubificidae sp. 1, Tubificidae sp. 2, Tubificidae sp. 3, Limnodrilus hoffmeisteri and $L$. udekemianus. Dero dorsalis constitute the first report for Kanchipuram district. A DNA barcode sequence (GenBank accession no. MF125273) of the commercially important Limnodrilus hoffmeisteri, commonly known as 'Tubifex worms' in Chennai, was obtained and compared with other published COI sequences from that morphospecies from around the world.
\end{abstract}

Key words: Freshwater oligochaetes, DNA barcode, Clitellata, COI, Tamil Nadu

\section{Introduction}

Studies on aquatic Oligochaeta from Tamil Nadu are scanty (Srinivasan et al. 2016). DNA barcode sequences of this group are absolutely lacking from this region, hence the objectives of this work are to 1) obtain a DNA barcode sequence of the commercially important freshwater oligochaete Limnodrilus hoffmeisteri and 2) to report on the diversity of aquatic Oligochaeta from some water bodies of Thiruvallur, Chennai, Kanchipuram, Villuppuram and Nilgiris districts of Tamil Nadu.

Study area and sampling sites (Figure 1): To understand the diversity of freshwater oligochaetes in

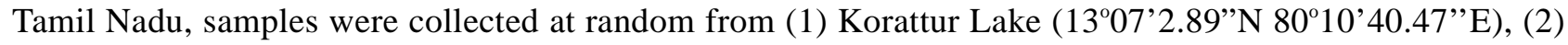

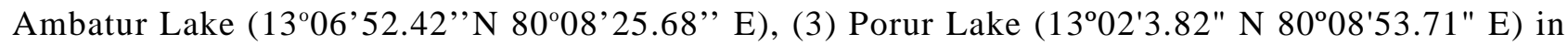

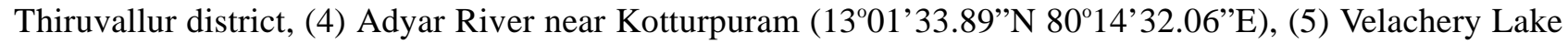

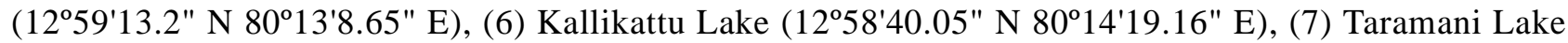

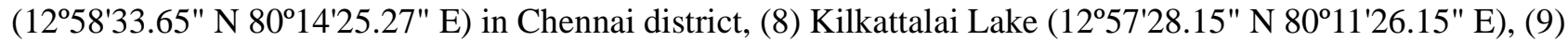

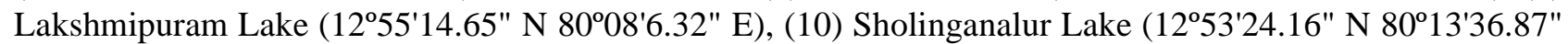
E), (11) Chengalpattu Lake (12 $41^{\prime} 31.62^{\prime \prime}$ N 7958'57.89" E) in Kanchipuram district, (12) Tindivanam Lake

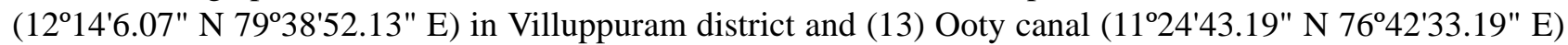
in Nilgiri district. Specimens for DNA studies were obtained from aquarium shops in Kolathur, Chennai. 


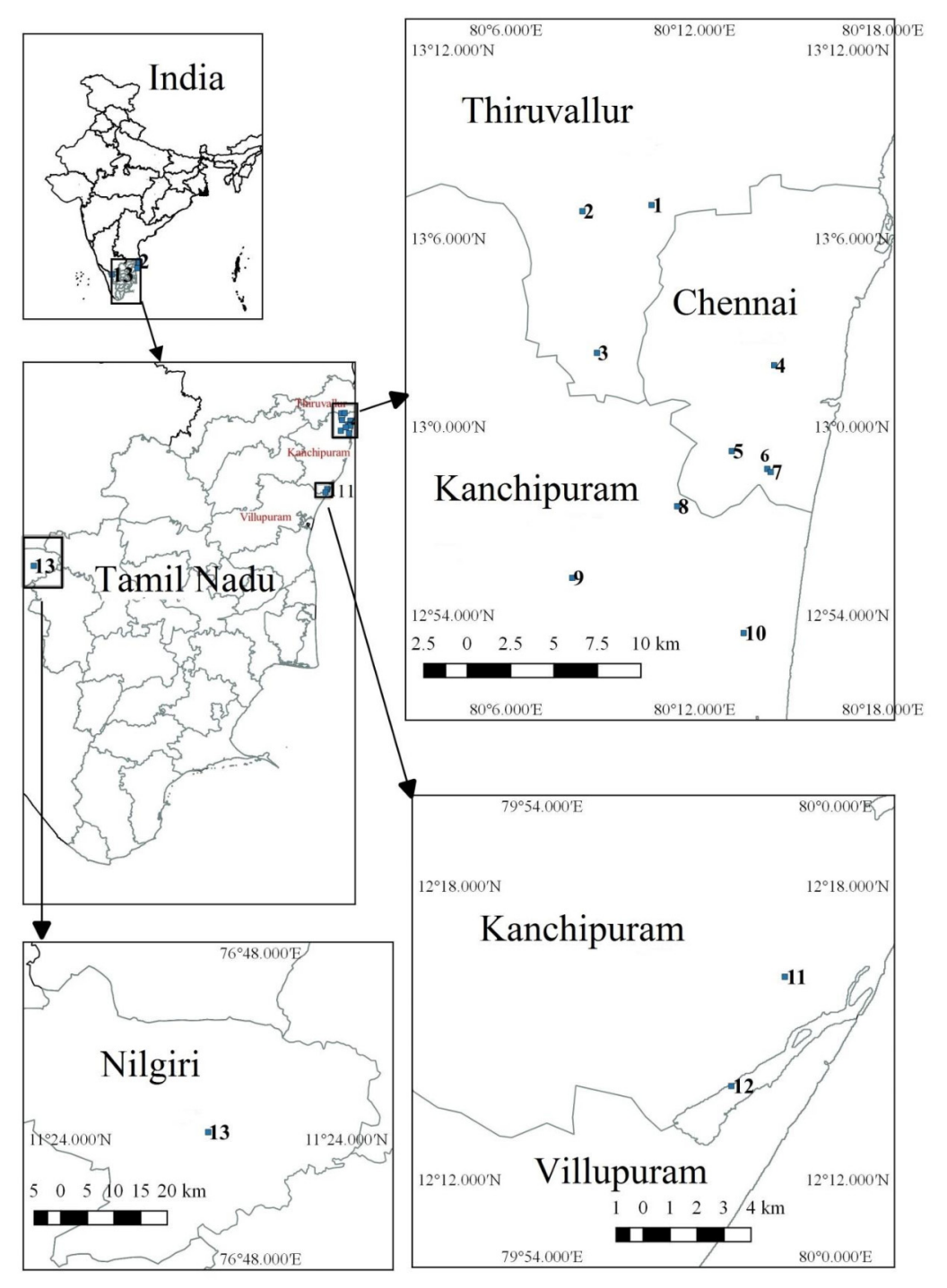

FIGURE 1. Map of sampling sites.

\section{Materials and methods}

Random sampling was done from October 2015 to June 2016, following the procedure of Srinivasan et al. (2016). Oligochaetes collected and separated from various aquatic vegetation and sediment samples were transferred into vials containing $10 \%$ formalin for preservation and storage. A few specimens collected from aquarium shops were preserved in $90 \%$ ethanol for sequencing studies as specimens preserved in formaldehyde cannot be used for sequencing (Haaren and Soors 2012). Live worms were examined under a cover slip in a drop of water. Preserved worms were mounted in a few drops of glycerin as temporary mounts for routine examination. A few permanent mounts were prepared using DMHF, also known as Hydantoin 739 or 5,5-Dimethylhydantoin Formaldehyde Resin. A phase contrast light microscope was used for examining the taxonomic characters. Identification of oligochaetes was done according to Brinkhurst and Jamieson (1971), Naidu (2005), Timm (2009) and Haaren and Soors (2012). Drawings were made using a compound microscope with camera lucida. For molecular studies the posterior tail region of a mature specimen identified as Limnodrilus hoffmeisteri was cut and preserved in 90\% ethanol. Molecular analyses of the ethanol preserved specimens were done at the Biozone Lab, Chennai, following a phenol chloroform protocol Pachamuthu et al. 2000. The standard barcoding gene COI was amplified with the primers COI-5 FORWARD GGTCAACAAATCATAAAGATATTGG ( 25 ) and COI-5 REVERSE TAAACTTCAGGGTG 
ACCAAAAAATCA ( 26 ), using the following PCR-program: initial denaturation at $94^{\circ} \mathrm{C}$ for 3 min followed with 32 cycles with $94^{\circ} \mathrm{C}$ for $1 \mathrm{~min}, 48^{\circ} \mathrm{C}$ for $1 \mathrm{~min}$, and $72^{\circ} \mathrm{C}$ for $1 \mathrm{~min} 20 \mathrm{sec}$, and finishing with the final extension at $72^{\circ} \mathrm{C}$ for $7 \mathrm{~min}$. DNA sequence obtained for identifying the specimen was compared to the database of known sequences in GenBank, using the Standard Nucleotide BLAST with default settings (search performed 2018-08-24). Analysis of the phylogenetic tree of our sequences and the 60 closest sequences from GenBank was estimated with Maximum Likelihood using MEGA 6 (Tamura et al. 2016). Initial tree(s) for the heuristic search were obtained automatically by applying Neighbor-Joining and BioNJ algorithms to a matrix of pairwise distances estimated using the Maximum Composite Likelihood (MCL) approach, and then selecting the topology with superior log likelihood value. The Tamura-Nei substitution model with a Gamma distribution were used. Branch support was estimated using 100 Bootstrap replicates.

The tree is drawn to scale, with branch lengths measured in the number of substitutions per site.

\section{Results}

In total 11 taxa were recorded from a total of 922 specimens examined. Out of the 11 taxa, 8 were identified to species level and three to family level. Dero dorsalis constitutes the first report for Kanchipuram district. The systematic account of the taxa identified is given below:

Systematic account with taxonomic observations of the specimens examined

\section{Family Naididae}

\section{Branchiodrilus semperi (Bourne, 1890)}

Specimen examined: Chengalpattu Lake (Kanchipuram), 24.4.2016 (1 specimen).

Taxonomic observations: Length: about $4 \mathrm{~mm}$. Worms brownish. Gills finger-like, dorso-lateral, two per segment starting from VI. Dorsal chaetae from VI. Hair chaetae smooth. Simple-pointed needle chaetae with a peculiar bayonet- shaped distal curve without nodulus (Figure 2A). Ventral chaetae 1-3 per bundle with distal tooth longer and thinner than proximal (Figure 2B). Posterior segments lacking gills from XX.

Remarks: Finger-like gills on the anterior part of the body and dark brown patch in the anterior segments were the most prominent character pointing towards $B$. semperi, which was originally described from Chennai (Madras) by Bourne (1890). However, it should be noted that Martin et al. (2018) concluded that the morphological characters used to separate the species in Branchiodrilus are not reliable, and that the number of species are much higher than previously believed. As our record is collected relatively close to the type locality it is possible that it represents the true B. semperi.

\section{Dero dorsalis Ferronière, 1899}

Specimens examined: Lakshmipuram Lake (Kanchipuram), 5.01.2016 (3 specimens) and 07.05.16 (10 specimens); Chengalpattu Lake (Kanchipuram), 24.4.2016 (3 specimens).

Taxonomic observations: Length $8-10 \mathrm{~mm}$. Dorsal chaetae begin from IV with 1 hair and 1 needle. Hair chaetae about 250 to $350 \mu \mathrm{m}$ long (Figure 2C). Needle chaetae bifid and bayonet-shaped, with distal tooth longer and thinner than proximal. Distal tooth longer and thinner than proximal also in the ventral chaetae (Figure 2D). Five pairs of gills observed in the branchial fossa.

Remarks: First report for Kanchipuram district.

\section{Dero digitata (Müller, 1773)}

Specimens examined: Porur Lake (Thiruvallur), 5.2.2016 (24 specimens). 

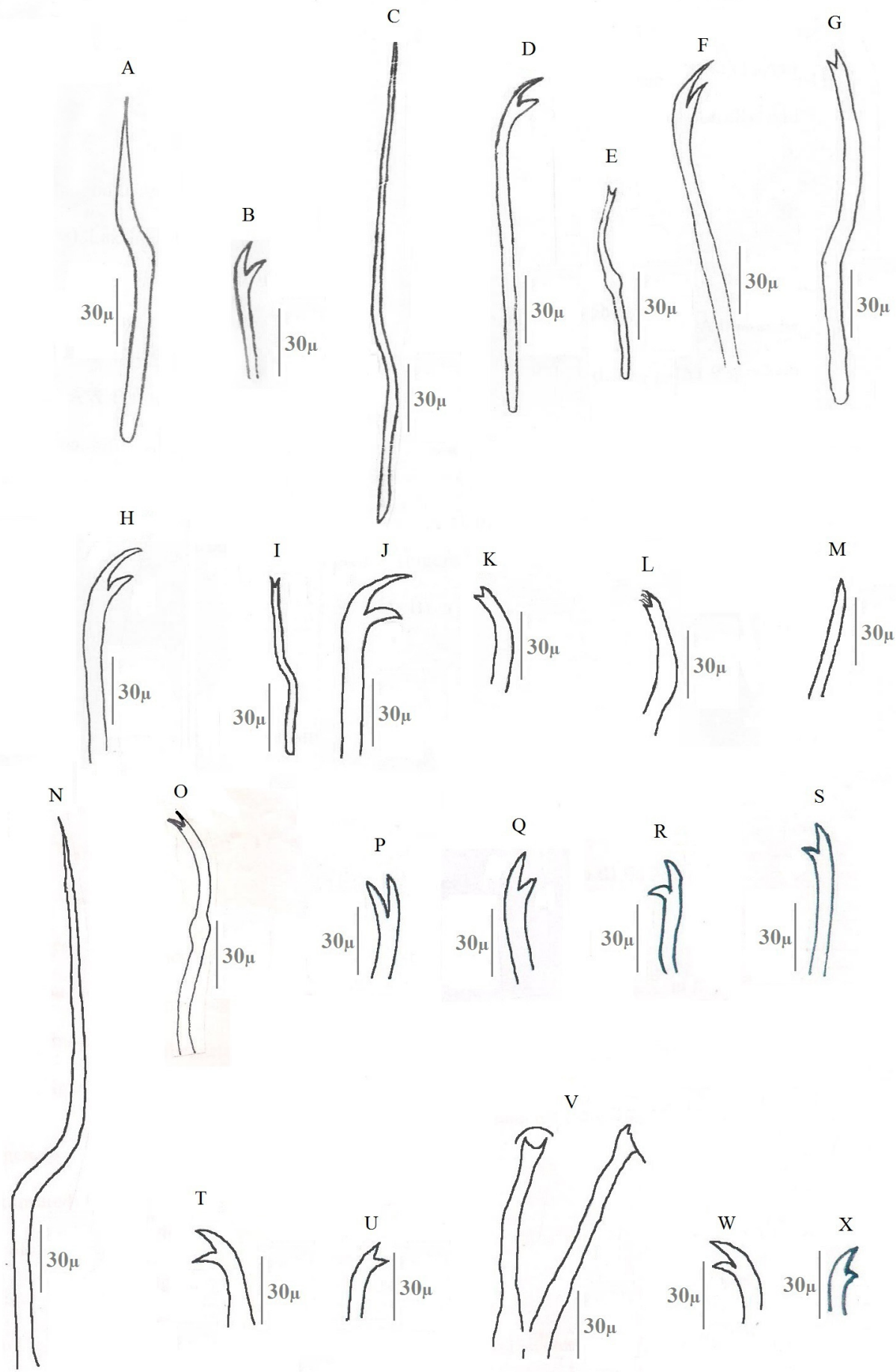

FIGURE 2. Branchiodrilus semperi: A) needle chaeta, B) ventral chaetae. Dero dorsalis: C) hair chaetae, D) ventral chaetae. Dero digitata: E) needle chaetae, F) ventral chaetae. Dero indica: G) needle chaetae, H) ventral chaetae. Dero zeylanica: I) needle chaetae, J) ventral chaetae Branchiura sowerbyi: K) Bifid chaetae, L) pectinate chaetae, M) Simple-pointed ventral chaetae. Tubificidae sp. 1: N) hair chaetae, O) dorsal needle chaetae. Tubificidae sp. 2 (Illydrilus templetoni?): P) dorsal chaetae, Q) ventral chaetae. Tubificidae sp. 3: R) dorsal chaetae, S) ventral chaetae. Limnodrilus hoffmeisteri: T) dorsal chaetae, U) ventral chaetae, V) penis sheaths. Limnodrilus udekemianus: W) dorsal chaetae, X) anterior ventral chaetae.

Taxonomic observations: Length 5 to $8 \mathrm{~mm}$. Worms red in colour. Dorsal chaetae from VI, ventral chaetae from II. The dorsal bundles consist of 1 hair and 1 needle chaeta. Needle chaeta are bifid, sickleshaped with distal nodulus (Figure 2E). Distal tooth of the needle chaeta is slightly thinner and longer than the proximal (Figure 2E). Ventral bundles in II-V consist of 4 long, thin and slightly curved chaeta per bundle 
with upper tooth longer than the lower (Figure 2F). In other segments 3-4 ventral chaetae per bundle, with upper tooth almost equal to lower. Four pairs of gills in the branchial fossa.

\section{Dero indica Naidu, 1962}

Specimens examined: Porur Lake (Thiruvallur),5.2.2016 (42 specimens), Lakshmipuram Lake (Kanchipuram), 7.5.2016 (12 specimens).

Taxonomic observations: Length 5 to $8 \mathrm{~mm}$. Worms red in colour. Dorsal chaetae from VI. Dorsal bundles with 2 hair and 2 needle chaetae. Needle chaeta bifid, sickle-shaped with distal nodulus. Distal tooth of the needle chaeta slightly thinner and longer than the proximal (Figure 2G). Ventral bundles from II-V consist of 4 long, thin and slightly curved chaeta per bundle with upper tooth longer than the lower (Figure $2 \mathrm{H})$. In other segments 3-4 ventral chaetae per bundle, with upper tooth almost equal to lower. Four pairs of gills observed in the branchial fossa.

\section{Dero zeylanica Stephenson, 1913}

Specimens examined: Porur Lake (Thiruvallur) on 5.2.2016 (10 specimens), Ambatur Lake (Thiruvallur) on 15.4.2016 (6 specimens), Chengalpattu Lake (Kanchipuram) on 20.4.2016 (9 specimens).

Taxonomic observations: Length 5-6 mm. Dorsal chaetae begin in VI, each bundle with 3 hair and 3 needle chaetae. Needle chaeta bifid, sickle-shaped with distal tooth longer than proximal (Figure 2I). Ventral chaetae in II-V 4-6 per bundle, longer and thinner, distal teeth twice as long as proximal (Figure 2J). In other segments ventral chaetae with almost equal teeth. Four pairs of gills observed in the branchial fossa.

Remarks: Dero digitata, D. indica and D. zeylanica differ in the number of dorsal chaetae. Further molecular studies are needed to distinguish them.

\section{Family Tubificidae}

\section{Branchiura sowerbyi Beddard, 1892}

Specimens examined: Lakshmipuram Lake, (Kanchipuram) on 16.12.2015 (7 specimens), Chengalpattu lake (Kanchipuram) on 24.04.2016 (2 specimens), Lakshmipuram Lake (Kanchipuram) on 07.05.2016 (15 specimens).

Taxonomic observations: Worms very large, about $90-120 \mathrm{~mm}$ long. Dorsal chaetae begin from II with 1-3 hairs and 2-8 needles. Needles bifid (Figure 2K). Bifid dorsal chaetae present (Figure 2L). Single-pointed ventral chaeta present (Figure 2M). One pair of gills per segment were observed in the posterior third of the body.

\section{Tubificidae sp. 1}

Specimens examined: Chengalpattu Lake (Kanchipuram) on 17.4.2016 (9 specimens).

Length about 12 to $16 \mathrm{~mm}$. Prostomium conical. Dorsal chaetal bundles from II with 1-4 hair and 5-6 bifid needle chaetae. Hair chaetae bayonet shaped (Figure 2N). Dorsal and ventral crotchets with distal teeth almost equal to the proximal (Figure 2O). Tail region unsegmented.

\section{Tubificidae sp. 2}

Specimens examined: Ooty canal (Nilgiris) on 1.06.2016 (3 specimens).

Taxonomic observations: Length 11 to $13 \mathrm{~mm}$. Segments 50 to 60. Dorsal crotchets bifid with about equal teeth (Figure 2P). Hair chaetae present. Anterior ventral chaetae 4-6 per bundle, with distal tooth much 
longer than proximal (Figure 2Q). In segments X-XII structures like egg sacs visible. Normal ventral chaetal bundles present in X. Well-developed, short clitellum in XI. No ventral chaetae visible in XI. No penis sheaths were observed but expanded (dorsal?) blood vessel in XII.

Remarks: These characters are insufficient to identify these specimens further, as no penis sheaths were observed, the identification remains with a question mark.

\section{Tubificidae sp. 3}

Specimen examined: Ooty canal, (Nilgiris) 01.06.2016 (1 specimen).

Taxanomic observations: Length about $12 \mathrm{~mm}$, segments about 43. Prostomium slightly protruded. Dorsal chaetae with 2 to 3 hair and 2 to 3 bifid crotchets with almost equal teeth (Figure 2R). Ventral chaetae 2-4 per bundle, with distal tooth longer than proximal (Figure 2S).

Remarks: The specimen seems to be a tubificid: very probably belonging to the subfamily Tubificinae (which includes genera and species with hair and pectinate chaetae such as Tubifex, Ilyodrilus, Potamothrix).

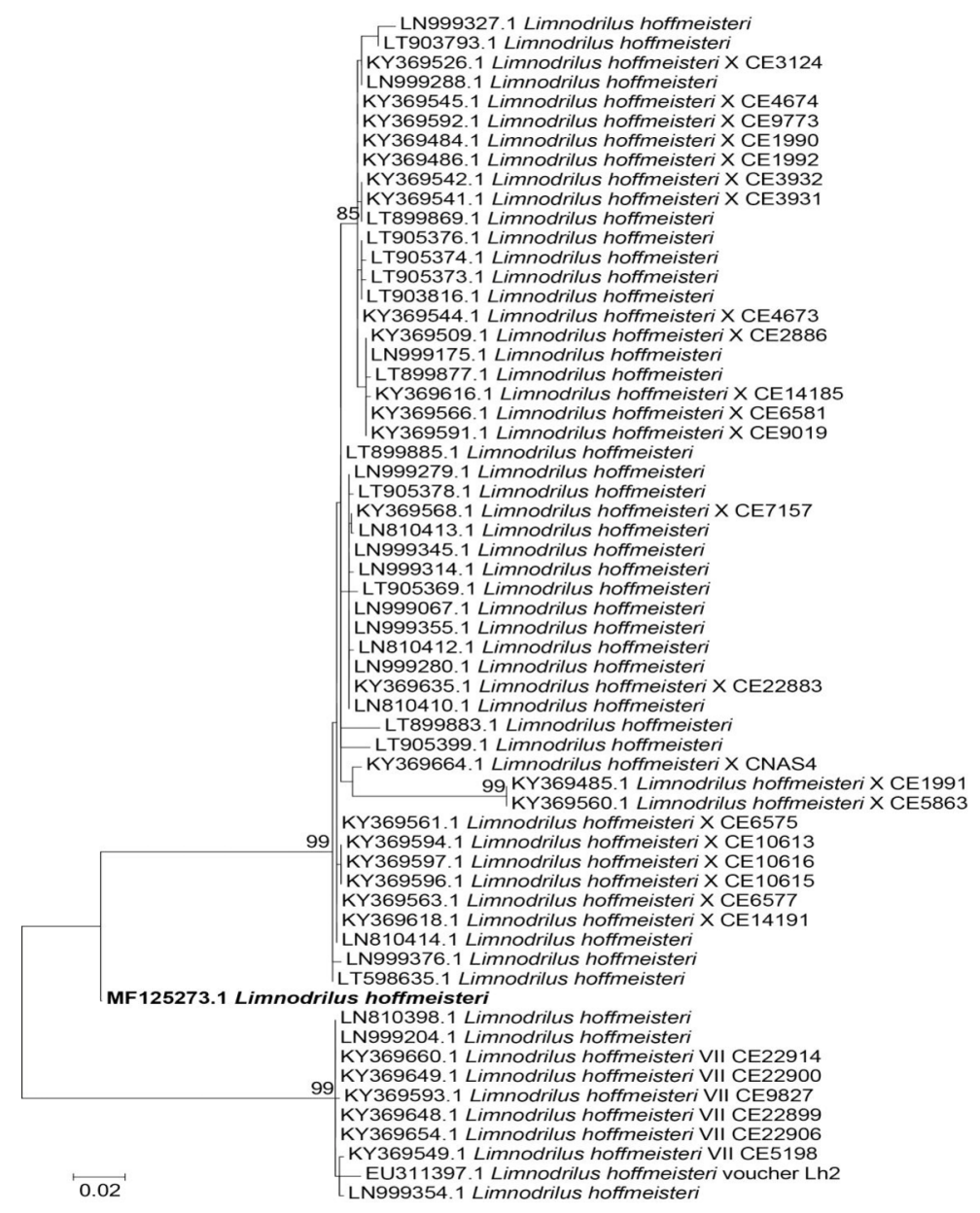

FIGURE 3. Phylogenetic Tree estimated using Maximum Likelihood. The percentage of trees in which the associated taxa clustered together is shown next to the branches.

\section{Limnodrilus hoffmeisteri Claparède, 1862}

Specimens examined: Lakshmipuram Lake (Kanchipuram) on 5.1.2016. (18 specimens), 10.1.2016 (12 specimens), Kallikattu Lake (Chennai) on 7.4.2017 (40 specimens), Kallikattu lake (Chennai) on 11.4.2016 (75 specimens), 13.4.2016 (63 specimens), Korattur Lake (Thiruvallur) on 26.4.2016 (2 specimens), Kilkattalai Lake (Kanchipuram) on 1.5.2016 (1 specimen). Ooty canal (Nilgiris) on 1.6.2016 (17 specimens), aquaria (Chennai) on 6.11. 2015 (500 specimens), Ootycanal (Nilgiris) on 1.06.2016(1 specimen). 
Taxonomic observations: Length about $12-35 \mathrm{~mm}$. Chloragogen beginning from V. Dorsal (Figure 2T) and ventral (Figure $2 \mathrm{U}$ ) crotchets similar, with about equal teeth. Ventral chaetae absent in XI. Penial sheaths 11-12 times longer than proximal width, curved distally. The penial sheaths (Figure 2V) of the specimen collected from Ooty canal showed slight variation from that of the specimen collected from Chennai.

Results of barcoding / molecular studies: A DNA barcode sequence, 670 bp long (GenBank accession no. MF125273) was obtained from one Limnodrilus hoffmeisteri. The sequence was compared to the 60 best matching sequences in GenBank. The tree with the highest log likelihood (-1959.4745) is shown (Figure 3). The closest matches with our sequences, on GenBank, correspond with lineages VII and X of the $L$. hoffmeisteri complex sensu Liu et al. 2017, but our sequence does not fit directly in any of these two lineages.

\section{Limnodrilus udekemianus Claparède, 1862}

Specimens examined: Ooty canal (Nilgiris) on 1.6.2016 (4 specimens).

Taxonomic observations: Worms long, about 35-47 mm. Both dorsal (Figure $2 \mathrm{~W}$ ) and ventral (Figure $2 \mathrm{X}$ ) crotchets similar. Anterior crotchets 3-8 per bundle with distal tooth thicker, much longer than proximal and curved. Crotchets in the posterior segments with teeth almost equal.

Remarks: This species differ from L. hoffmeisteri in having a long curved distal tooth in the anterior chaetae and in general the worms were much larger than L. hoffmeisteri and the chloragogen began on the intestine.

\section{Discussion}

Thirteen species of aquatic Oligochaeta are known from Chennai, 4 from Thiruvallur, 4 from Kanchipuram, 7 from Villuppuram and 15 from Nilgiris districts of Tamil Nadu. About 34 species of aquatic Oligochaeta have been reported from Tamil Nadu by Srinivasan et al. 2016. Out of the 5 naidids reported in the present study Dero dorsalis constitute the first report for Kanchipuram district. Hence, the present paper adds one species to Kanchipuram district.

Out of the 6 Tubificids reported in the present study, Branchiura sowerbyi and Limnodrilus hoffmeisteri are cosmopolitan in distribution. In Tubificidae sp. 1 the hair chaetae are like most Aulodrilus sp. Three species belonging to the genus Aulodrilus have been described from the Indian sub-continent by Naidu (2005). It is not excluded that this can be an undescribed species of Aulodrilus. In the specimen identified as Tubificidae sp. 2, the morphological characters do not contradict (but are insufficient for identification) as the widely distributed Tubifex tubifex, or some closely related species since no penis sheaths were observed. The species identified as Tubificidae sp. 2 needs further examination by collecting more such mature specimen with well-developed reproductive system. Limnodrilus udekemianus collected from Ooty canal was first reported in India by Naveed (2012). This species has longer proximal teeth in the crotchets when compared to L. hoffmeisteri.

Ragi and Jaya (2014) reported that Dero sp. were the most abundant in their study from Kerala, (South India) and a similar situation was also observed during the present survey in most of the district of Tamil Nadu except the cold region of Nilgiri district where tubificid worms were more common.

A DNA barcode sequence (mitochondrial COI (Cytochrome c Oxydase 1)) obtained from a mature specimen of Limnodrilus hoffmeisteri is closest to lineage VII and X of the L. hoffmeisteri complex sensu Liu et al. (2017). However, it is not a direct match to any of these two lineages and it is possible that it is an additional lineage within the complex that deserves to be treated as a separate species. To further test this more data is needed.

There are also several cryptic species known in Branchiodrilus (Martin et al. 2018) and Dero (Erseus et al. 2017) and molecular studies are needed to confirm the identifications of the species in these genera. The three Dero species Dero digitata, D. indica and D. zeylanica differ mainly in the number of dorsal chaeta, and molecular studies are needed to test if these differences are stable between species, or if it varies within species, blurring the lines between these species.

Though the present work is a humble attempt to explore the biodiversity of aquatic Oligochaeta from Thiruvallur, Chennai, Kanchipuram, Villupuram and Nilgiris it gives some idea about the composition of this 
group in the areas studied and suggests that more undescribed aquatic oligochaetes exist in Ooty and this area needs to be surveyed to discover many new species. This work is a humble beginning in the field of molecular taxonomy of aquatic oligochaetes from India and a lot of questions are yet to be understood. Though the present work is a preliminary attempt, it provides a DNA barcode sequence of the commercially important Limnodrilus hoffmeisteri commonly called as 'Tubifex worms' and provides sufficient support to the morphological identification of this species.

\section{Acknowledgements}

We are grateful to Dr. Tarmo Timm, Senior Researcher, Estonian University of Life Sciences for his guidance and valuable suggestions. We are grateful to Dr. Akifumi Ohtaka, Symposium Host and Organizer of the $14^{\text {th }}$ International Symposium on Aquatic Oligochaeta, Mr. Mark J Wetzel, General Secretary, ISAO and Dr. Christer Erséus for their encouragement support and help. We are grateful to the management, Principal and Head, Department of Zoology, The New College, Chennai for providing necessary facilities to carry out this work.

\section{References}

Brinkhurst, R.O. \& Jamieson, B.G.M. (1971) Aquatic Oligochaeta of the World. Oliver and Boyd, Edinburgh, 860 pp.

Erséus, C., Envall, I., De Wit, P. \& Gustavsson, L.M. (2017) Molecular data reveal a tropical freshwater origin of Naidinae (Annelida, Clitellata, Naididae). Molecular Phylogenetics and Evolution, 115, 115-127. https://doi.org/10.1016/j.ympev.2017.07.016

Haaren, T.V. \& Soors, J. (2012) Aquatic oligochaetes of the Netherlands and Belgium. KNNV Publishing, Zeist, The Netherlands, $302 \mathrm{pp}$.

Liu, Y., Fend, S.V., Martinsson, S. \& Ersejus, C. (2017) Extensive cryptic diversity in the cosmopolitan sludge worm Limnodrilus hoffmeisteri (Clitellata, Naididae). Organisms Diversity \& Evolution, 17, 477-495. https://doi.org/10.1007/s13127-016-0317-z

Martin, P., Martinsson, S., Wuillot, J. \& Erséus, C. (2018) Integrative species delimitation and phylogeny of the branchiate worm Branchiodrilus (Clitellata, Naididae). Zoologica Scripta, 47 (6), 727-742. https://doi.org/10.1111/zsc.12316

Naidu, K.V. (2005) The Fauna of India and the adjacent countries - Aquatic Oligochaeta. Zoological Survey of India, Kolkata, 294 pp.

Naveed, M.I. (2012) Preliminary studies on aquatic Oligochaeta in and around Chennai, Tamil Nadu. Turkish Journal of Zoology, 36, 25-37.

Pachamuthu, P., Kamble, S.T., Clar, T.L. \& Foster, J.E. (2000) Differentiation of three phenotypically similar Blattella spp.: analysis with polymerase chain reaction restricted fragment length polymorphism of mitochondrial DNA. Annals of the Entomological Society of America, 93, 1138-1146. https://doi.org/10.1603/0013-8746(2000)093[1138:DOTPSB]2.0.CO;2

Ragi, M.S. \& Jaya, D.S. (2014) Distribution and diversity of oligochaetes in selected ponds of Thiruvananthapuram district, Kerala, South India. Advances in Ecology, 2014, 1-9. https://doi.org/10.1155/2014/138360

Srinivasan, S., Ramalingum, S. \& Naveed, M.I. (2016) Preliminary survey of freshwater Oligochaeta from selected districts in Tamil Nadu (India). Biologia, 71, 64-69. https://doi.org/10.1515/biolog-2016-0011

Tamura, K., Stecher, G., Peterson, D., Filipski, A. \& Kumar, S. (2013) MEGA6: Molecular Evolutionary Genetics Analysis version 6.0. Molecular Biology and Evolution, 30, 2725-2729. https://doi.org/10.1093/molbev/mst197

Timm, T. (2009) A guide to the freshwater Oligochaeta and Polychaeta of Northern and Central Europe. Lauterbornia, 66, 1235. 